\title{
Are bigger calamary Sepioteuthis australis hatchlings more likely to survive? A study based on statolith dimensions
}

\author{
M. A. Steer ${ }^{1,3, *}$, G. T. Pecl ${ }^{2}$, N. A. Moltschaniwskyj ${ }^{1}$ \\ ${ }^{1}$ School of Aquaculture, Tasmanian Aquaculture and Fisheries Institute, University of Tasmania, Private Bag 370, Launceston, \\ Tasmania 7520, Australia \\ ${ }^{2}$ Marine Research Laboratories, Tasmanian Aquaculture and Fisheries Institute, University of Tasmania, Private Bag 49, \\ Hobart, Tasmania 7001, Australia \\ ${ }^{3}$ Present address: Marine Research Laboratories, Tasmanian Aquaculture and Fisheries Institute, University of Tasmania, \\ Private Bag 49, Hobart, Tasmania 7001, Australia
}

\begin{abstract}
To determine whether any size-selective processes were operating throughout the life history of squid, this study set out to ascertain whether bigger hatchlings are more likely to survive to adulthood. This was achieved by comparing natal statolith dimensions between recently hatched $(<13 \mathrm{~h}$ old) and successfully recruited adult Sepioteuthis australis. The squid statolith (analogous to the teleost otolith) retains a check associated with hatching, and the natal radius (NR) at hatching had a strong linear relationship to dorsal mantle length (ML). Hatchlings were collected using emergent traps from October 2001 to February 2002 on natural spawning grounds located on the east coast of Tasmania. Hatchling size was extremely variable ranging from 4.3 to $7.3 \mathrm{~mm}$ (ML), with significantly larger squids hatching out in November and the smallest in February. From February to August, adults were collected from the same bay and aged using validated daily rings in the statolith and those adults estimated to have been born between October and February were included in the analysis. In all but $1 \mathrm{mo}$, a significant difference between the NR size distributions of the hatchlings and adults was detected due to low numbers of adults with small NRs. This indicated that smaller hatchlings were less likely to recruit, suggesting that there is an element of size-mediated mortality operating on populations of $S$. australis.
\end{abstract}

KEY WORDS: Squid $\cdot$ Hatchling $\cdot$ Statolith $\cdot$ Hatch-check $\cdot$ Natal-ring $\cdot$ Size-selection

\section{INTRODUCTION}

Given the short life span $(<1$ yr) and low fecundity of neritic squid, high survival rates during the early life history are essential to guarantee that recruitment failure does not occur. However, currently, there are no estimates of juvenile mortality rates for neritic squid and it is not clear whether size at hatching is important in survivorship. In the fish literature, it is widely suggested that fast growing and rapidly developing larvae attain larger sizes earlier, thereby lowering their risk of size-dependent mortality (Johannessen et al. 2000). There are a number of theories supporting why this is the case and they collectively attribute it to faster growing fish accelerating through the window of vulnerability associated with being small and poorly developed (Fogarty et al. 1991). Furthermore, this potential for faster growth may be present at hatching, with larger hatchlings displaying an 'athletic' edge compared to their smaller siblings (Meekan \& Fortier 1996). Similarly, some individuals may be more likely to survive based on other physical, behavioural or physiological characteristics (Rice et al. 1993).

Studies exploring size-selective mortality in teleost fish have used otolith dimensions to estimate the length of an individual. This is achieved by generating 
a predictive relationship between otolith size and fish size, and allowing the size of that fish at an earlier stage of its life history to be estimated (Francis 1990). This approach, however, may fail if there is an uncoupling between somatic and otolith growth (Molony \& Choat 1990, Mosegaard 1990). Establishing a link between otolith size and larval size at hatching may be more appropriate in addressing size-selective processes, although difficult in wild fisheries due to poor availability of recently hatched larvae. Weak positive correlations between otolith size and hatchling size for laboratory reared Atlantic cod Gadus morhua (Miller et al. 1999) and wild-caught juvenile Sockeye Salmon Oncorhynchus nerka (West \& Larkin 1987) do not provide reliable predictions to estimate hatchling size from adult otoliths. However, constraining the data so that it is stock- and season-specific may potentially account for some of the variability and improve the predictive power of this approach (Miller et al. 1999).

In squid populations, establishing and identifying characteristics of successful recruits in nonoverlapping generations may lead to improved forecasts of each year's population strength. This is particularly pertinent in the face of increasing worldwide cephalopod fishing pressure (Roper \& Rathjen 1991). Squid statoliths are structurally and functionally analogous to fish

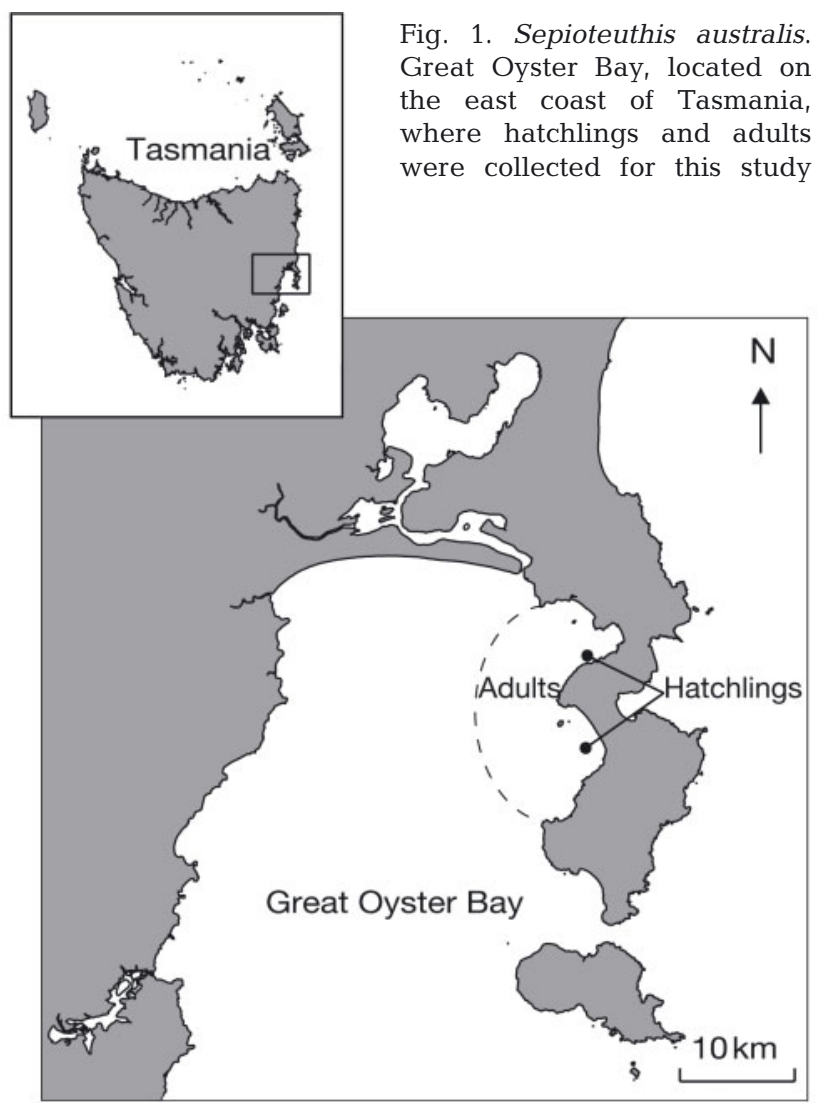

otoliths, and as a result many of the ageing and growth techniques used in fish otolith analysis are applicable in squid (Jackson 1994). Linear relationships (of varying strengths) between statolith dimensions and body size and weight at hatching are evident for some laboratory reared cephalopods (i.e. Sepioteuthis lessoniana: Ikeda et al. 1999, Jackson \& Moltschaniwskyj 2001; Loligo vulgaris, Loligo forbesi: Martins 1997). Loliginid squid generally display a distinct anomaly in the statolith structure associated with the day of hatching, e.g. 'hatch-check' or 'natal ring', (Villanueva et al. 2003). The retention of this anomaly in the adult statolith potentially provides a way of estimating an adult's size at hatching from the size of the statolith radii at hatching (Ikeda et al. 1999). This method potentially provides a powerful tool for exploring the 'bigger is better' hypothesis by collecting hatchlings over the spring/summer spawning period and adults 3 to 4 mo later, and then comparing the size frequency of the hatch check radii.

The primary aim of this study was to investigate whether size-selective mortality was operating during the squid Sepioteuthis australis life history. If not, then the size frequency of the natal statoliths in recent hatchlings and those preserved in adults would be similar. If, however, size-selective mortality has occurred with bigger hatchlings being more likely to survive, then the natal radius (NR) size distribution of the adult statolith would be expected to be further to the right of the hatchling NR size distribution. The advantage of this approach is that it is field-based and avoids any biases associated with the potential uncoupling of somatic and statolith growth. To reduce the variability associated with stock- and season-specific effects, we limited collection of hatchlings and adults to specific areas and times of the year.

\section{MATERIALS AND METHODS}

Validation of hatchling statolith and somatic relationships. Recent $(<13 \mathrm{~h}$ old) Sepioteuthis australis hatchlings were collected from inshore spawning beds located within Great Oyster Bay, Tasmania (Fig. 1) from late October 2001 to early February 2002, excluding January due to poor weather. Great Oyster Bay represents a unique area, as it accommodates the majority of $S$. australis spawning activity on the east coast of Tasmania, comprising 50 to $70 \%$ of Tasmania's commercial catch (Lyle \& Hodgson 2001). It was therefore assumed that squid hatching out in Great Oyster Bay were highly likely to use the same area to spawn as adults.

Hatchlings were captured using purpose-built emergent traps, which were placed and anchored over egg masses from which individuals were hatching. Traps 
were constructed from $1.5 \mathrm{~mm}$ mesh and $<1.0 \mathrm{~mm}$ perforated plastic collection vials that retained all hatchlings. Five emergent traps were deployed on shallow $(<4 \mathrm{~m})$ productive spawning beds in Great Oyster Bay within $10 \mathrm{~km}$ of each other (Fig. 1). Each trap was inspected twice a day (at ca. 08:00 and 19:00 h) over 4 consecutive d per month. Captured hatchlings were taken ashore and immediately preserved in $70 \%$ ethanol. Each hatchling was weighed $(\mathrm{g})$ and dorsal mantle length (ML) measured (mm) using a stereo dissector and eyepiece graticule. Statoliths were removed from the hatchlings by decapitating the squid and teasing each statolith from the exposed statocyst chamber. Statoliths were rinsed in $100 \%$ ethanol to remove excess tissue, air-dried and whole mounted on the posterior plane in Crystal Bond ${ }^{\circledR}$ thermoplastic cement.

Natal statolith total length (TL) and NR, measured from the nucleus to the statolith margin perpendicular to the longitudinal axis (Fig. 2), were measured using a high power binocular microscope and Scion image analysis computer program. These dimensions were chosen because these natal ring dimensions can be reliably measured in prepared adult statoliths, depending on whether they have been ground transversely or dorso-ventrally. To determine whether there was a difference in dimensions between the left and right statoliths, both statoliths from 50 random hatchlings were measured and compared using paired $t$-tests. No difference was detected for either TL $(t=$ $0.56, \mathrm{df}=49, \mathrm{p}=0.58)$ or NR $(t=-0.15, \mathrm{df}=49, \mathrm{p}=$ $0.88)$; therefore, only 1 statolith was used from the remaining hatchlings. To determine the reliability of the measured linear dimensions, a second person measured TL and NR in 20 to 25 statoliths. No reader bias was evident for either linear dimensions (TL: $t=1.72$, $\mathrm{df}=24, \mathrm{p}=0.12$; NR: $t=1.73, \mathrm{df}=19, \mathrm{p}=0.09$ ).

Measuring the natal radius in adults. Adults were caught in Great Oyster Bay (within a $10 \mathrm{~km}$ radius from where hatchlings were collected) from February to August. Unfortunately, in 2002, low numbers of adults were caught $(n=24)$, therefore adults caught from 1996 to 2001 were used. For the purposes of this study, it was assumed that year-to-year variation was minimal; however, this will require further investigation. Each individual was processed fresh; sexed, weighed, measured (ML) and both statoliths were extracted, rinsed in $100 \%$ ethanol and stored dry. Grinding an adult statolith down to the focus on the lateral plane allows TL and NR to be measured. However, the natal statolith's rostrum is occasionally obscured by the growth of the wing, preventing measurement of TL. Grinding to the focus dorso-ventrally was adopted in this study due to the precision required for measuring NR. Statoliths were whole mounted in Crystal Bond ${ }^{\circledR}$ thermoplastic cement with the ventral dorsal dome projecting over the edge of the glass slide. The statolith was then ground along a transverse plane, using wet $1200 \mu \mathrm{m}$ carborundum paper, until the plane passed through the statolith nucleus. The ground surface was polished with $0.05 \mu \mathrm{m}$ alumina powder on wet suede polishing cloth. The extent and intensity of grinding was continually monitored using a binocular light microscope (40×). The polished surface was mounted so that the rostrum was aligned perpendicular to the slide's surface. The statolith was ground and polished to a section thin enough for examination. Statoliths were heat treated on a hot plate for 1 to $2 \mathrm{~min}$ to accentuate the natal ring and increments. Age estimates were determined from daily increments in the statolith (validated for Sepioteuthis australis by Pecl 2000). Adults estimated to have been born between October and February were used in the analysis. From the dorso-ventral plane, the natal ring (representing the boundary of the hatchling statolith) and the statolith nucleus are evident. The NR, measured from the nucleus to the maximum width of the natal ring was measured using Scion image analysis.

\section{RESULTS}

\section{Hatchlings}

A total of 364 Sepioteuthis australis hatchlings were collected from the Great Oyster Bay region from October through to February. Overall, hatchling ML ranged from 4.33 to $7.33 \mathrm{~mm}$ with significant differences in size among months $\left(F_{3,360}=82.24, \mathrm{p}<0.001\right)$. November

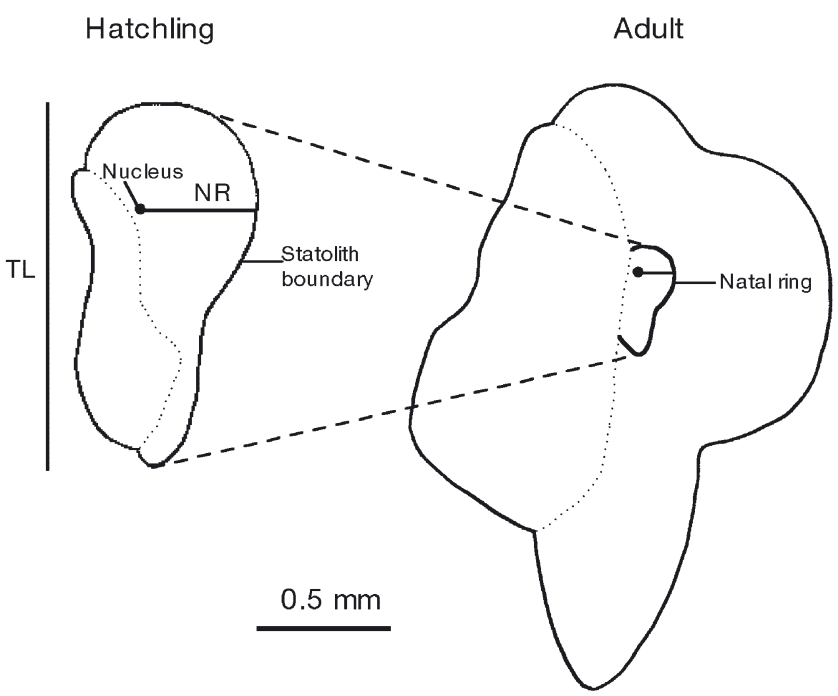

Fig. 2. Sepioteuthis australis. Hatchling and adult statoliths. Illustration highlights the preservation of the natal statolith in the adult form. Natal radius (NR) and total length (TL) are indicated on the hatchling statolith 


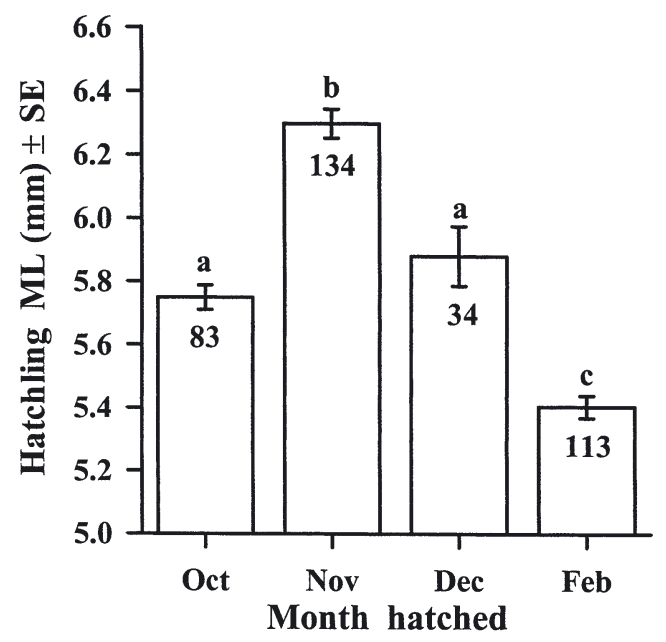

Fig. 3. Sepioteuthis australis. Mean hatchling mantle length $(\mathrm{ML}) \pm \mathrm{SE}$ over the sampling period. Lower case letters indicate significant difference amongst means via a post-hoc

Tukey's test. Numbers indicate sample size

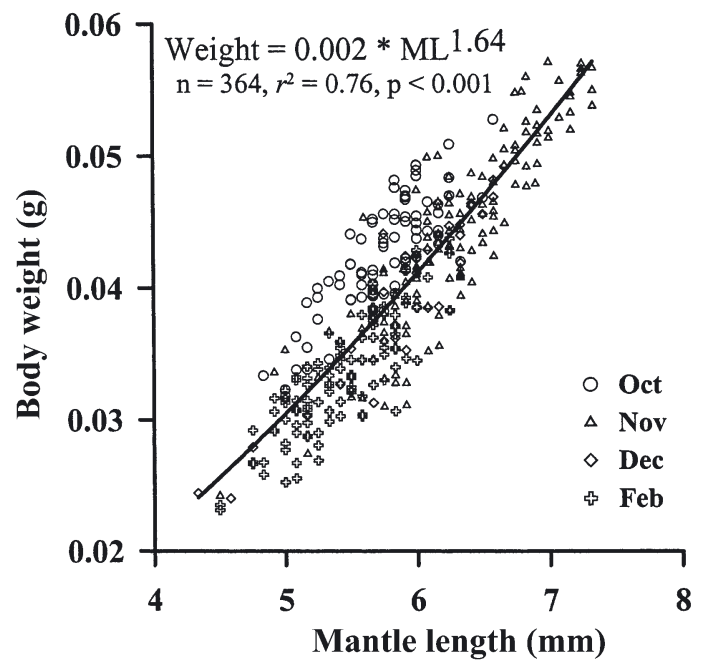

Fig. 4. Sepioteuthis australis. Hatchling length-weight relationship. Power regression formula is provided for total sample. Data points have been coded to represent sampling month hatchlings were as much as 4 to $14 \%$ larger than hatchlings in any other month, with the smallest hatchlings in February (Fig. 3). The hatchling lengthweight relationships were not significantly different among the months (ANCOVA: $\left.F_{3,356}=1.50, \mathrm{p}=0.21\right)$, indicating that the rate of increase in weight with length was similar among months (Fig. 4). A large proportion of hatchlings $(\sim 60 \%)$ collected in October were observed to have retained their external yolk sac, suggesting they had been stimulated to hatch prematurely by prevailing weather conditions. Taking these premature October hatchlings into consideration, it was apparent that hatchling size decreased with increasing seasonal temperatures.

At least 1 statolith was successfully dissected from 348 (95.1\%) hatchlings and the NR measured. In some cases $(10.9 \%)$, the statolith rostrum either cracked or crumbled during the dissection process, consequently TL was measured from 310 individuals. Both measured statolith dimensions (NR and TL) were significantly and positively related to hatchling length and weight (Fig. 5). In general, larger hatchlings had larger statoliths; however, the 2 statolith dimensions varied in their predictive power. Hatchling NR was the strongest predictor
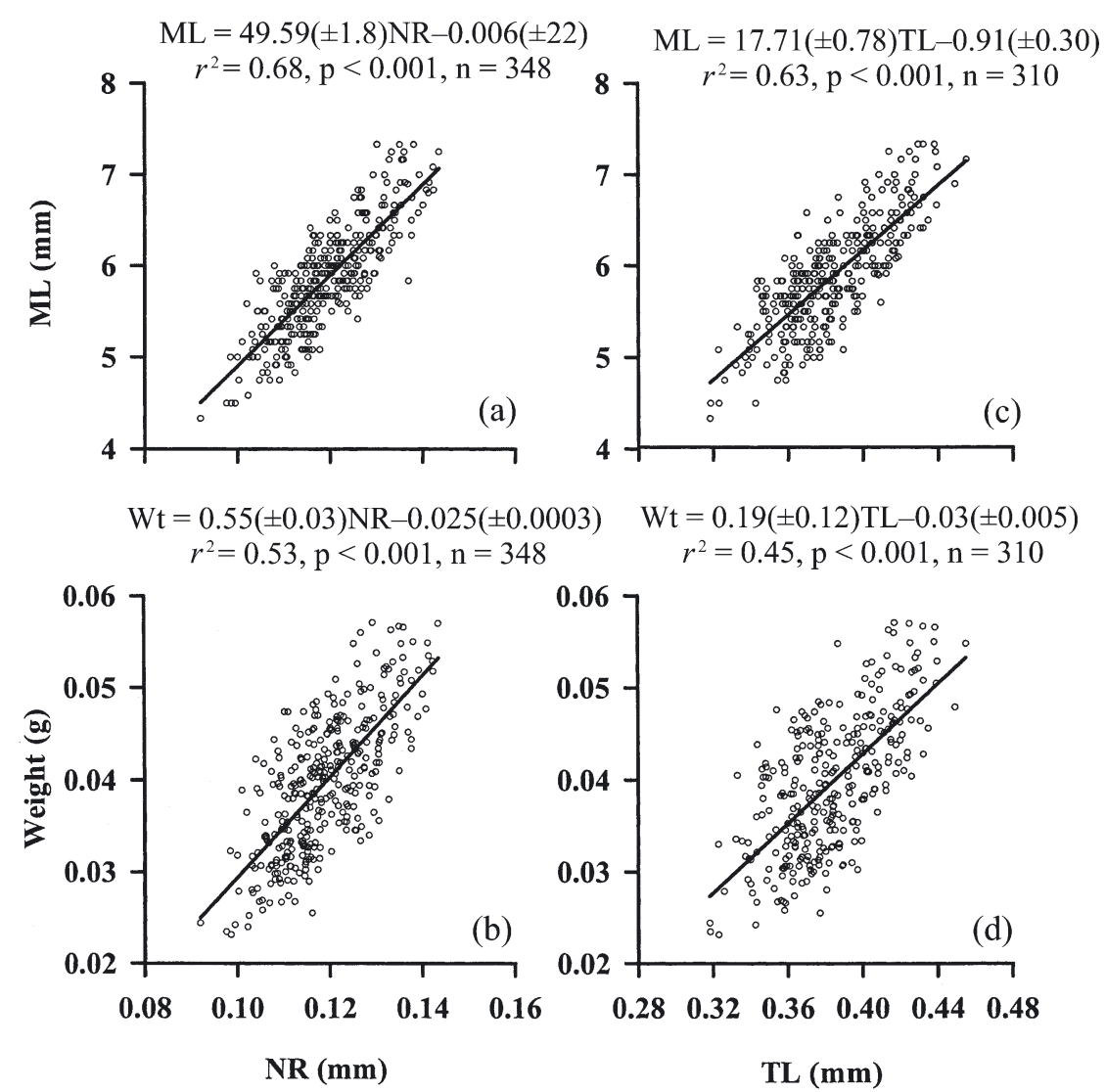

Fig. 5. Sepioteuthis australis. Linear regressions between statolith dimensions, total length (TL) and statolith radius (NR) with hatchling mantle length (ML) and weight. Regression equations are provided to indicate each comparison's relative strength 
of $\mathrm{ML}$, explaining $68 \%(\mathrm{n}=348)$ of the variation in $\mathrm{ML}$, whereas TL explained slightly less (63\%) of the variation in ML $(\mathrm{n}=310)$. A similar trend was observed for hatchling weight; however, the predictive power was weaker, explaining 53 and $45 \%$ of the variation, respectively.

\section{Comparison of successful recruits and recent hatchlings}

A total of 269 Sepioteuthis australis adults were successfully aged and subsequently calculated to have hatched in the target months (Oct to Feb, except Jan). There were significant differences between NR size frequency distributions between hatchlings and adults in each birth month, except in November (Fig. 6). When significant differences were detected, there were proportionally more adults with NRs in the larger size classes, resulting in distributions that were shifted to the larger end of the size spectrum. In total, $42.53 \%$ of all the collected hatchlings had NRs $>0.12 \mathrm{~mm}$ compared with $73.13 \%$ of the adults, demonstrating the differences in the size distributions.

No significant difference was detected in the adult NR size distributions among the months (mean =
Table 1. Sepioteuthis australis. Pairwise comparisons of the size frequency distributions of natal radius (NR) measurements in adult statoliths between months via a series of Kolmogorov-Smirnov (Z-statistic) tests

\begin{tabular}{|lccc|}
\hline Comparison & $\mathrm{n}$ & $Z$ & Sig \\
\hline October vs November & 105 & 1.013 & 0.256 \\
October vs December & 143 & 1.149 & 0.143 \\
October vs February & 134 & 0.623 & 0.832 \\
November vs December & 134 & 0.506 & 0.960 \\
November vs February & 125 & 0.924 & 0.361 \\
December vs February & 163 & 1.027 & 0.242 \\
\hline
\end{tabular}

$0.125 \mathrm{~mm}$ ) (Table 1). Using the validated ML/NR regression equation, a hatchling with an average NR of $0.125 \mathrm{~mm}$ would have a predicted ML of $6.19 \pm 0.05$ (95\% CL), which was $5.8 \%$ larger than the average size of the trapped hatchlings $(5.85 \pm 0.06)$.

A series of Pearson's correlations between adult biological parameters and predicted hatchling size were used to identify any biological characteristics of adults that would explain their survival. Correlations between predicted hatchling size with adult ML (mm), adult weight $(\mathrm{g})$ and calculated residuals from the adult length-weight relationship were all weak and
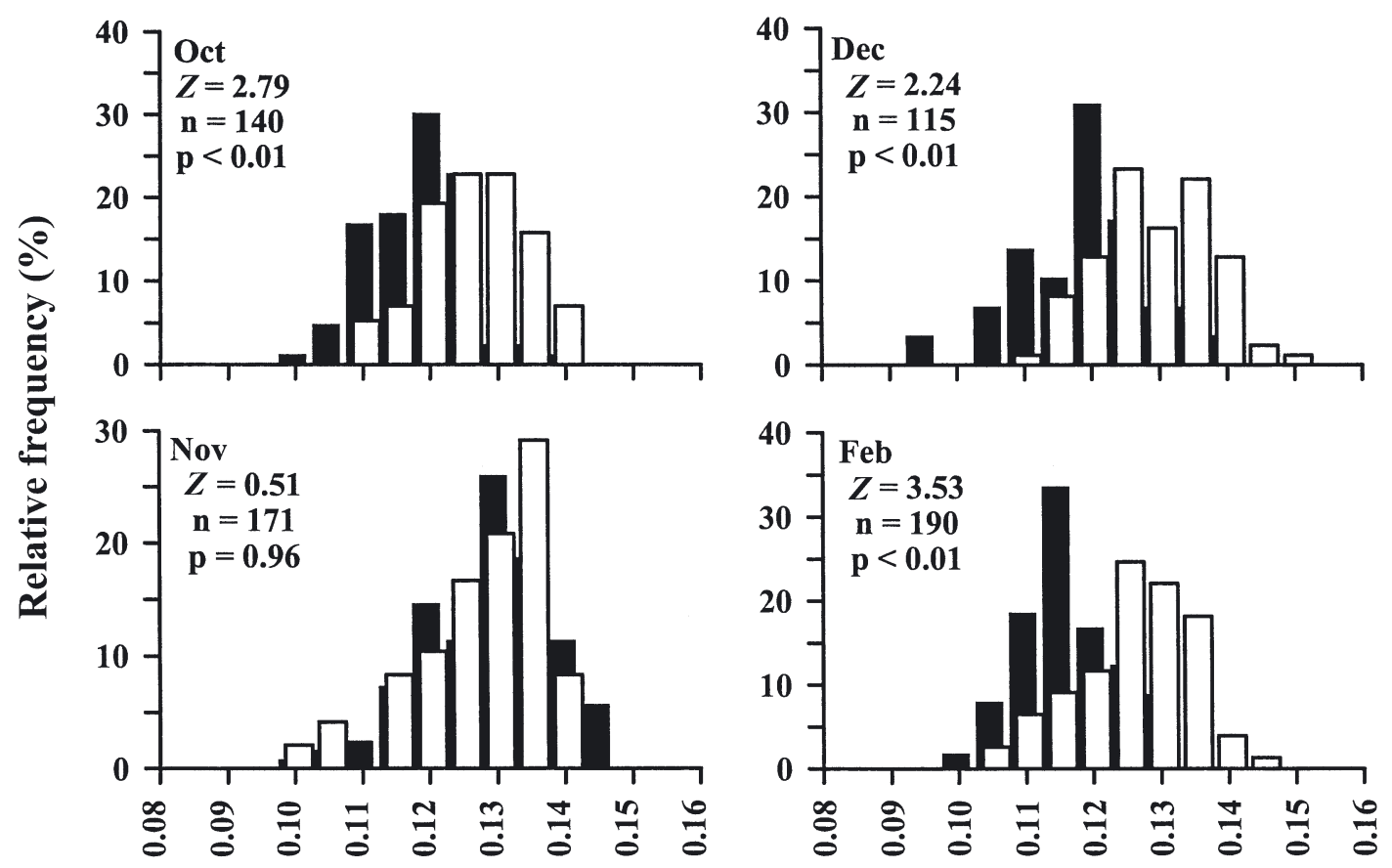

\section{Natal statolith radius $(\mathrm{mm})$}

Fig. 6. Sepioteuthis australis. Monthly natal statolith radius (NR) length frequency histograms plotted for wild-caught hatchlings (black bars) and adults (white bars). Each graph includes a Kolmogorov-Smirnov (Z-statistic) test exploring differences between 
non-significant (ML: $r=0.12, \mathrm{n}=239, \mathrm{p}=0.06$; weight: $r=0.09, \mathrm{n}=239, \mathrm{p}=0.17$; residuals: $r=-0.08, \mathrm{n}=243$, $\mathrm{p}=0.22$ ). Similarly, no difference was detected when comparing the predicted hatchling size distributions between sexes (Kolmogonov-Smirnov [Z-statistic] test: $Z=0.74, \mathrm{n}=210, \mathrm{p}=0.65)$, suggesting that no sexual dimorphism is evident at hatching.

\section{DISCUSSION}

In general, larger Sepioteuthis australis hatchlings had larger statoliths, and there was a positive relationship between NR and ML. The natal ring and nucleus preserved in adult statoliths were clear enough to measure NR, and in 3 of the $4 \mathrm{mo}$, the adult NRs were found to be larger than the hatchling NRs.

In this study, we made 2 major assumptions. The first related to the formation of the natal ring at hatching; an assumption that is supported throughout the literature (Natsukari \& Komine 1992, Villanueva et al. 2003) and has been validated for Sepioteuthis australis through the rearing of known-age squids in captivity (Pecl 2000). The second assumption was that there was minimal annual variation in hatchling size; this allowed us to compare adults hatched from 1996 to 2001, with hatchlings from 2001. However, there was an absence of adults with small NRs, inferring smaller sizes at hatching. This suggests a degree of size-selective mortality or non-random predation was operating throughout the early life history. Interestingly, no significant difference was detected in the predicted size at hatching across months. Most of the adults were estimated to have a hatched $\mathrm{ML}>6.19 \mathrm{~mm}$, with hatchlings smaller than this poorly represented. Although it is impossible to attribute the loss of these individuals directly to size-selective predation from the data obtained, these results suggest that the smallest hatchlings failed to recruit into the fishery.

Sepioteuthis australis hatchlings are the largest of the loliginids, having relatively advanced behavioural and functional attributes (Steer et al. 2003). Despite this, they are still susceptible to a suite of predators throughout their entire life and as a result are considered an important link in the marine ecosystem (Gales et al. 1994). Size-selective mortality is observed in a variety of marine species that exhibit broad variability in size and this phenomenon is often referred to as the 'bigger is better' hypothesis, where average mortality rates decrease with age and body size as the individual's sensitivity to starvation decreases and its foraging success and swimming abilities improve (Conover \& Schultz 1997). However, there is potential for individuals to grow out of one window of vulnerability for a particular type of predator and enter into another, suggesting that there may be continuous non-random predation, with animals always running the gauntlet. A purely size-based predation model is considered an oversimplification of the inter-connected processes involved in the marine ecosystem as there are naturally many other contributing factors (Cowan \& Shaw 2002). Local hydrodynamics, availability of food, intolerance to extreme environmental conditions, susceptibility to disease/parasites as well as fishing pressure may also be responsible for elevated mortality (Sogard 1997), with some of these continuing to operate with an element of size-selectivity.

Due to the large proportion ( 60\%) of premature hatchlings collected in the October sample, differences in the size distributions may be exaggerated. Size-selective mortality was not strongly evident during November, coinciding with the beginning of the 'hatching' season. However, there was a progressive shift in the frequency distributions between hatchlings and successful recruits in subsequent months. West \& Larkin (1987) observed similar trends for salmon Oncorhynchus nerka, with mortality increasing in intensity through late summer to early autumn; this was attributed to size-mediated predation and parasitism. However, the correlation between fish and otolith length was considered too weak $\left(r^{2}<0.2\right)$ to attribute losses purely to size-selective mortality and it was suggested that other parameters such as weight and age be incorporated in the model to reduce biases (Mosegaard 1990). The relationship between statolith radius and hatchling length in this study was comparatively stronger $\left(r^{2}=0.68\right)$, and although the susceptibility of juveniles to parasites was not investigated, exaggerated differences in the size compositions may be in part attributed to density dependent effects. Large variation in hatchling sizes existed over the extended hatching period (also see Villanueva et al. 2003); therefore larger, older and more competent individuals have the capacity to cannibalise their smaller and younger conspecifics, a phenomenon evident in haddock Melanogrammus aeglefinus and bluefin tuna Thunnus maccoyii populations (Perry \& Nielson 1988, Young \& Davies 1990). Cephalopods are cannibalistic throughout most life stages, especially when food is limited, and there is evidence of intra-cohort cannibalism in Sepioteuthis hatchlings, where larger hatchlings readily attack and consume smaller conspecifics, both in the wild (G. T. Pecl unpubl. data) and in captivity (Walsh et al. 2002). Given that calamary spawn over a protracted season, the risk of mortality for hatchlings due to cannibalism may be heightened as the season progresses and egg density increases (see Moltschaniwskyj \& Pecl 2003), potentially accounting for the increasing differences observed in this study. Alternatively, differences may 
be attributed to temporal shifts in productivity and available prey, directly challenging paralarvae upon their switch from an endogenous to exogenous mode of feeding (Cushing 1975).

Complementing the data from this research with pre-recruit studies will determine whether natural mortality is greatest during the early life stages (Type III mortality curve: Pearl \& Miner 1935) or whether predation occurs at a continuous rate throughout their entire life history (Type II). Pre-recruit, larval abundance studies on the oceanic ommastrephid Todarodes pacificus indicated that this species exhibited a Type III mortality curve where rhynchoteuthion larvae measuring $\leq 6 \mathrm{~mm}$ ML suffered higher mortality than larvae $>6 \mathrm{~mm}$ (Okutani \& Watanabe 1983). This shift is suggested to correspond with the end of the rhynchoteuthion stage and a period when diel migration is critical to the larvae. Sepioteuthis australis possess 2 maternally derived yolk sacs: the external yolk sac is typically depleted pre-hatching, however, the internal yolk sac sustains the hatchling for a short period posthatch (Steer et al. 2003). Although calamary do not undergo metamorphosis, the switch in feeding modes may represent a similar critical period accounting for improved survival rates post $6.19 \mathrm{~mm}$.

It has been suggested that in a population where size differences are maintained and juvenile size is a good predictor of adult size, selective fishing mortality removing relatively large individuals could obscure the interpretation of the data (Sogard 1997). Other than size at hatching, there was no strong evidence of other biological parameters present in the adults that provided an indication of their 'athletic' edge. The adult population was relatively heterogeneous with all explored correlates, with hatchling size yielding insignificant results. The ability of squid to quickly respond to their immediate environment in terms of growth and reproduction (Hatfield 2000, Jackson \& Moltschaniwskyj 2002) may potentially cloud any functional correlations with hatchling size. Furthermore, a comparison of purse-seine (non-selective) and jigging (potentially selective) sampling techniques yielded no significant difference in the size composition of captured squid (Moltschaniwskyj et al. 2003), suggesting that there were no associated collection biases in this study and the results obtained truly reflect size-dependent mortality. A concern associated with the interpretation of the data, however, relates to the amount of variability explained by the predictive regression model. Although on the whole the model is not poor, a degree of error was assumed to be incorporated as a function of measuring very small hatchlings and statolith dimensions. It has been suggested that statolith area may potentially improve the model by reducing the amount of error associated with measur- ing linear dimensions (Meekan et al. 1998). The methodology involved in measuring the area of the natal statolith preserved in adults has not yet been refined, but is theoretically possible when grinding the statolith laterally. Although the exact processes involved in size-selective mortality in southern calamary are unclear, such estimates provide valuable insights into the dynamic processes and the vulnerability of small squid that can potentially be used as a proxy to predict recruitment strength.

Acknowledgements. Thanks to D. Sinn, S. Tracey and T. Jantzen for valuable field and laboratory assistance. The authors also thank 4 anonymous reviewers for constructive comments which greatly improved the manuscript. M.A.S was supported by a University of Tasmania Research Scholarship with supplementary funding from the Tasmanian Aquaculture and Fisheries Institute. All field expenses were met by a concurrent project funded by the Fisheries Research and Development Council (2000/121) awarded to N.A.M.

\section{LITERATURE CITED}

Conover DO, Schultz ET (eds) (1997) Natural selection and evolution of growth rate in the early life history: What are the trade-offs? Chapman \& Hall, London

Cowan JH, Shaw RF (2002) Recruitment. In: Fuiman LA, Werner RG (eds) Fishery science: the unique contributions of early life stages. Blackwell Scientific Publications, Oxford, p 88-111

Cushing DH (1975) Marine ecology and fisheries. Cambridge University Press, London

Fogarty MJ, Sissenwine MP, Cohen EB (1991) Recruitment variability and the dynamics of exploited marine populations. TREE 6:241-245

Francis RICC (1990) Back-calculation of fish length a critical review. J Fish Biol 36:883-902

Gales R, Pemberton D, Lu CC, Clarke MR (1994) Cephalopod diet of the Australian fur seal: variation due to location, season and sample type. Aust J Mar Freshw Res 44: 657-671

Hatfield EMC (2000) Do some like it hot? Temperature as a possible determinant of variability in growth of the Patagonian squid, Loligo gahi (Cephalopoda: Loliginidae). Fish Res 47:27-40

Ikeda Y, Wada Y, Nobuaki A, Sakamoto W (1999) Note on size variation of body and statoliths in the oval squid Sepioteuthis lessoniana hatchlings. J Mar Biol Assoc UK 79: $757-759$

Jackson GD (1994) Application and future potential of statolith increment analysis in squids and sepioids. Can J Fish Aquat Sci 51:2612-2625

Jackson GD, Moltschaniwskyj NA (2001) The influence of ration level on growth and statolith increment width of the tropical squid Sepioteuthis lessoniana (Cephalopoda: Loliginidae): an experimental approach. Mar Biol 138: 819-825

Jackson GD, Moltschaniwskyj NA (2002) Spatial and temporal variation in growth rates and maturity in the IndoPacific squid Sepioteuthis lessoniana (Cephalopoda: Loliginidae). Mar Biol 140:747-754

Johannessen A, Blom G, Folkvord A (2000) Differences in growth pattern between spring and autumn spawned 
herring (Clupea harengus L.) larvae. Sarsia 85:461-466

Lyle JM, Hodgson K (2001) Tasmania scalefish fishery assessment-2000. TAFI Tech Rep No. 19, p 1-60

Martins MC (1997) The statolith of Loligo vulgaris and Loligo forbesi hatchlings: preliminary morphological study. Vie Milieu 47:171-176

Meekan MG, Fortier L (1996) Selection for fast growth during the larval life of Atlantic cod Gadus morhua on the Scotian Shelf. Mar Ecol Prog Ser 137:25-37

Meekan MG, Dobson JJ, Good SP, Ryan DAJ (1998) Otolith and fish size relationships, measurement error, and sizeselective mortality during the early life of Atlantic salmon (Salmo salar). Can J Fish Aquat Sci 55:1663-1673

Miller TJ, Herra T, Leggett WC (1999) The relation between otolith size and larval size at hatching for Atlantic cod, Gadus morhua. Fish Bull 97(2):294-305

Molony BW, Choat JH (1990) Otolith increment widths and somatic growth rates: presence of a time lag. J Fish Biol 37 : $541-552$

Moltschaniwskyj NA, Pecl GT (2003) Small-scale spatial and temporal patterns of egg production by the temperate loliginid Sepioteuthis australis. Mar Biol 142:509-516

Moltschaniwskyj N, Pecl G, Lyle J, Haddon M, Steer M (2003) Population dynamics and reproductive ecology of the southern calamary (Sepioteuthis australis) in Tasmania. FRDC Final Report (2000/121), Townsville, p 163

Mosegaard H (1990) What is reflected by otolith size at emergence? A re-evaluation of the results in West and Larkin (1987). Can J Fish Aquat Sci 47:225-228

Natsukari Y, Komine N (1992) Age and growth estimation of the European squid, Loligo vulgaris, based on statolith microstructure. J Mar Biol Assoc UK 72:271-280

Okutani T, Watanabe T (1983) Stock assessment by larval surveys of the winter population of Todarodes pacificus Steenstrup (Cephalopoda: Ommastrephidae), with a review of earlier works. Biol Oceanogr 2:401-431

Pearl R, Miner JR (1935) Experimental studies on the duration of life. XIV. The comparative mortality of certain lower

Editorial responsibility: Otto Kinne (Editor),

Oldendorf/Luhe, Germany organisms. Q Rev Biol 10:60-79

Pecl GT (2000) Comparative life history of tropical and temperate Sepioteuthis squids in Australian waters. PhD thesis, James Cook University, Queensland

Perry RI, Nielson JD (1988) Vertical distributions and trophic interactions of age- 0 Atlantic cod and haddock in mixed and stratified waters of Georges Bank. Mar Ecol Prog Ser 49:199-214

Rice JA, Miller TJ, Rose KA, Crowder LB, Marschall EA, Trebitz AS, DeAngelis DL (1993) Growth rate variation and larval survival: Inferences from an individual-based size-dependent predation model. Can J Fish Aquat Sci 50: 133-142

Roper CFE, Rathjen W (1991) World-wide squid fisheries: a summary of landings and capture techniques. J Ceph Biol 2(1):51-63

Sogard S (1997) Size-selective mortality in the juvenile stage of teleost fishes: a review. Bull Mar Sci 60:1129-1157

Steer MA, Moltschaniwskyj NA, Jordan, AR (2003) Embryonic development of southern calamary (Sepioteuthis australis) within the constraints of an aggregated egg mass. Mar Freshw Res 54:217-226

Villanueva R, Arkhipkin A, Jereb P, Lefkaditou E, Lipinski MR, Perales-Raya C, Riba J, Rocha F (2003) Embryonic life of the loliginid squid Loligo vulgaris: comparison between statoliths of Atlantic and Mediterranean populations. Mar Ecol Prog Ser 253:197-208

Walsh LS, Turk PE, Forsythe JW, Lee PG (2002) Mariculture of the loliginid squid Sepioteuthis lessoniana through seven successive generations. Aquaculture 212:245-262

West CJ, Larkin PA (1987) Evidence for size-selective mortality of juvenile Sockeye Salmon (Oncorhynchus nerka) in Babine Lake, British Columbia. Can J Fish Aquat Sci 44: 712-721

Young JW, Davies TLO (1990) Feeding ecology of larvae of southern bluefin, albacore and skipjack tunas (Pisces: Scombridae) in the eastern Indian Ocean. Mar Ecol Prog Ser 61:17-29

Submitted: January 22, 2003; Accepted: August 12, 2003 Proofs received from author(s): October 13, 2003 